\title{
MASiliti \\ Evaluation Report Sandia \\ Plutonium Protection System Operational Demonstration
}

\author{
G. E. Wilbur
}

November 1978

Prepared for the United States

Department of Energy

Under Contract EY-77-C-06-1030

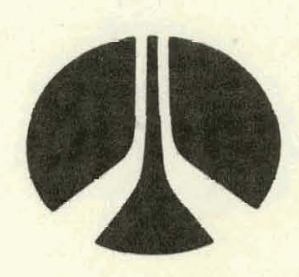

Rockwell International

Rockwell Hanford Operations

Energy Systems Group

Richland, WA 99352 


\section{DISCLAIMER}

This report was prepared as an account of work sponsored by an agency of the United States Government. Neither the United States Government nor any agency Thereof, nor any of their employees, makes any warranty, express or implied, or assumes any legal liability or responsibility for the accuracy, completeness, or usefulness of any information, apparatus, product, or process disclosed, or represents that its use would not infringe privately owned rights. Reference herein to any specific commercial product, process, or service by trade name, trademark, manufacturer, or otherwise does not necessarily constitute or imply its endorsement, recommendation, or favoring by the United States Government or any agency thereof. The views and opinions of authors expressed herein do not necessarily state or reflect those of the United States Government or any agency thereof. 


\section{DISCLAIMER}

Portions of this document may be illegible in electronic image products. Images are produced from the best available original document. 


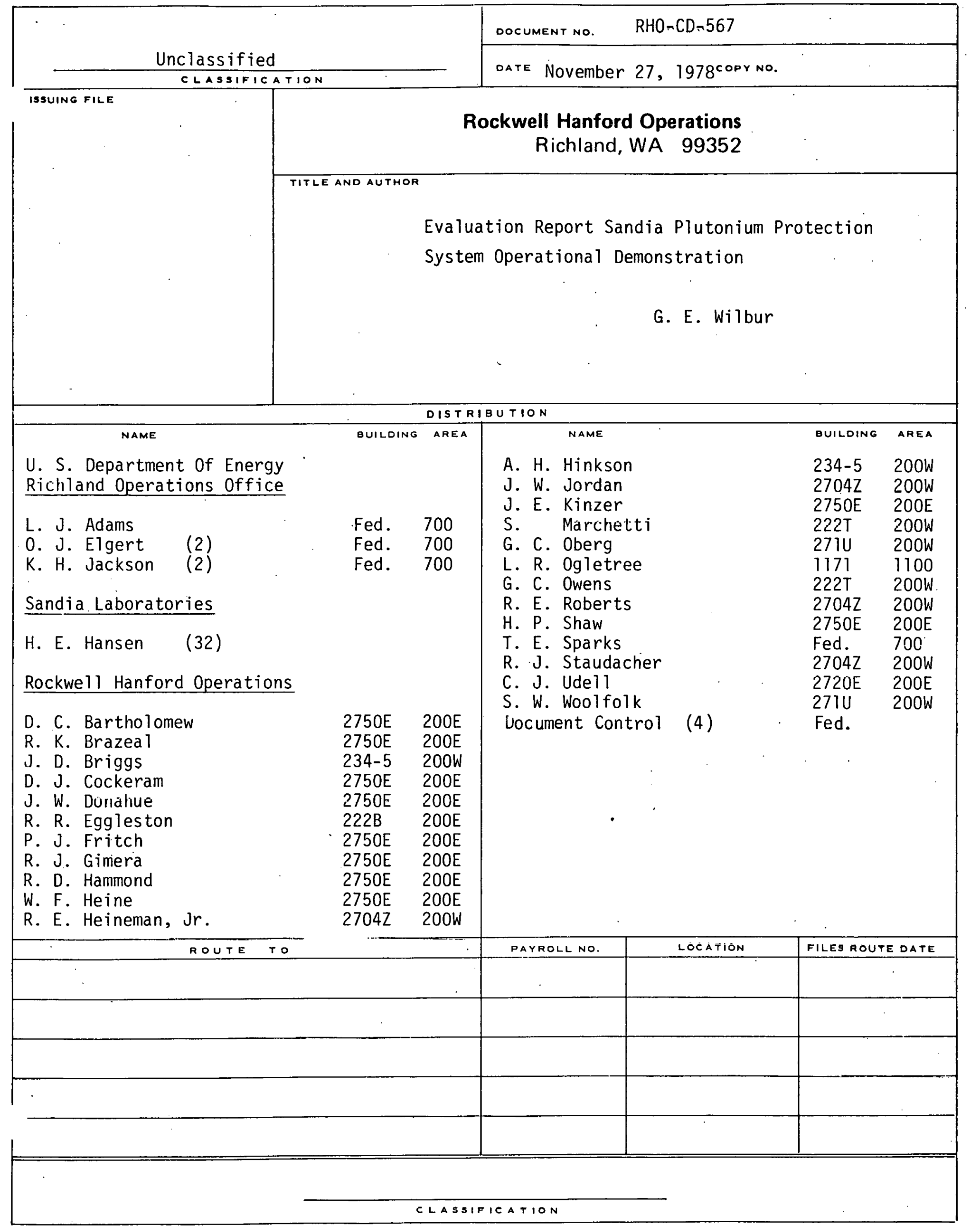


EVALUATION REPORT

SANDIA PLUTONIUM PROTECTION SYSTEM

OPERATIONAL DEMONSTRATION

SAND78-0660

G. E. WILBUR

NOVEMBER 27,1978

SAFEGUARUS DEPARTMENT

SAFEGUARDS ANALYSIS

$\&$

DEVELOPMENT GROUP 


\section{ABSTRACT}

Sandia Laboratories of Albuquerque, New Mexico, has developed an advanced plutonium storage system. The system provides protection for and accountability of material in storage and controls personnel access to storage areas. This storage system has been installed and operationally demonstrated at the Rockwell Hanford Operations Z-Plant facility. All demonstration transactions were performed by Z-Plant personnel. The demonstration was carried out to evaluate the system operation using special nuclear material in an operational environment. This document is the evaluation report of the operational demonstration. 
PREFACE

The Plutonium Protection System (PPS) is a safeguards development project performed by Sandia Laboratories, Albuquerque, New. Mexico for the Department of Energy. The overall project goal was to design and build for evaluation, a prototype plutonium storage system integrating safeguards concepts with advanced technology. The resultant system, designed to be compatible with a Hanford storage facility, has been subjected to safeguards and performance testing. The latter includes a realistic operational demonstration using plutonium and performed by appropriate Rockwell Hanford Operations personnel.

Relative to existing systems, the PPS is designed to provide improved protection, control and accountability of packaged material and to provide more rigid control of personnel access. It consists of three control centers for operations, accountability and security; a material packaging area; a secure material transport capability; and a hardened vault storage area with entry control, intrusion detection, and assessment systems.

Operation of the PPS is controlled by three computer centers (Figure 1): The Material Accountability Center, the Materials Cperations Center, and the Security Operations Center. Operating as an integrated system, these centers provide stringent control and rapid accountability for each package of plutonium. Access to and movement of plutonium are dependent upon operational interaction of the three control centers which are designed not 
only to separate the accountability, operations, and security functions, but also to create overlapping responsibilities for system reliability and an inherent set of checks and balances. These centers are interconnected by a data communications network. Activities within the PPS are covered by four types of transactions: (1) deposit, (2) in-vault movement, (3) withdrawal and (4) inspection/ maintenance. When a particular transaction has been authorized, the appropriate data is entered into the system, thus establishing a transaction file. Data from this file are used by each computer center to set up and assure that conduct of the transaction proceeds only as authorized.

Rockweil presently seals plutonium items in food pack cans for storage. In the PPS, plutonium containing cans are further sealed into an overpack container. Integrated into the upper half of each container are logic circuits and sensors to provide unit identification, material security, safety, and rapid inventory. Integral to the lower half is a security tang for the purpose of locking the container in its storage location.

In the packaging area each container is logged into the system data base and the presence of a threshold amount of radioactive material is verified. Containers are then moved by a secure transporter to the vault area for storage. The vault area houses the secure storage modules which provide secure storage space for the plutonium, control access to the plutonium, and provide the final link for maintaining plutonium accountability and inventory. 
The secure storage modules are designed to provide in-depth protection (i.e., a vault within a vault) for the plutonium. Each module contains four storage carrousels within a massive structure that has walls of pre-cast, steel-reinforced concrete and steel doors. Each carrousel contains 35 storage slots in a cylindrical configuration designed for single-container-only access and positive locking of each container. Rotation of each carrousel is computer-controlled to allow only the prescribed container to be released at the appropriate time. While in the storage carrousels, the status of each container is continuously monitored by a microprocessor in communication with the material accountability computer.

A succession of security checks must be satisfied before personnel are allowed to enter the vault area. An integrated entry-control, intrusion-detection, and assessment system is designed to detect unauthorized entry attempts and verify proper personnel access. Major elements of this system include an electronic credential reader, closed circuit TV cameras, an identification booth, metal and SNM detectors and motion sensors.

In the design of the PPS software, provisions have been made for supervised contingency operations to allow manual recovery in the event of personnel errors or system malfunctions.

Testing and evaluation of the PPS have been conducted in two phases; performance and safeguards. A major part of the performance test data is derived from the operational demonstration conducted by Rockwell Hanford Operations at Richland, Washington. 
The Plutonium Protection System final report, SAND78-0660, is published in six volumes as follows:

Volume I: Executive Summary
Volume II: System Operation
Volume III: Hardware Description,
Volume IV:
Volume Voftware Description
Volume VI: $\begin{gathered}\text { Operational Demonstration } \\ \text { \& Evaluation* }\end{gathered}$

In addition to these volumes, a large number of detailed technical. reports have been published. These are referenced in the appropriate volumes. A complete bibliography of Plutonium Protection System reports is included in the Executive Summary, Volume I.

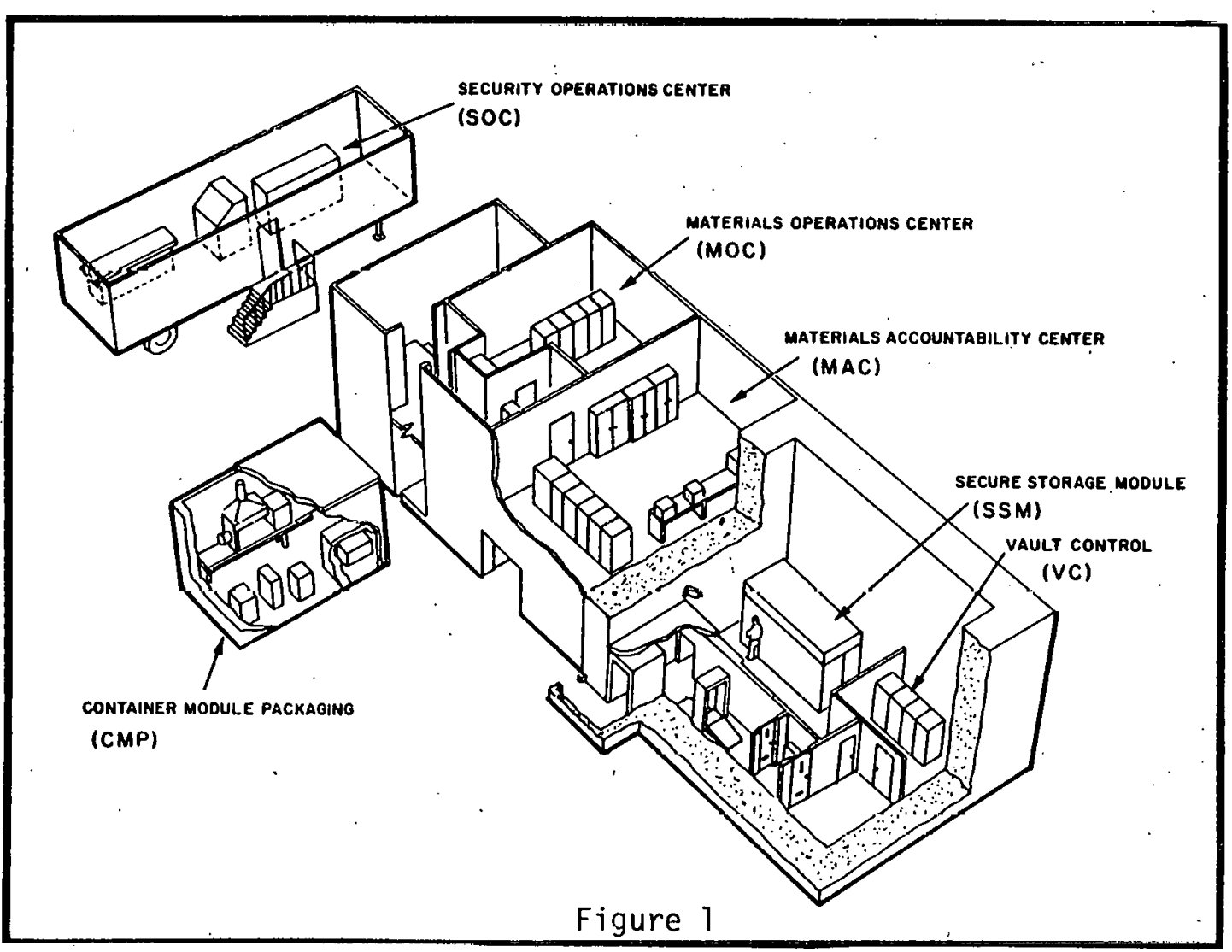




\section{ABSTRACT}

PREFACE

TABLE OF CONTENTS

vi

ACRONYMS

ix

SUMMARY

DEMONSTRATION PLAN

Phase I - Loading Operations.

Phase II - Storage Operations

Phase III - Withdrawal Operations

Implementation of Demonstration Plan

DESIGN EVALUATION

Operative Statement

Design Criteria

Safeguards

Protection In Depth

Release of SNM

Real Time Inventories

Reduction of Personnel Exposure

Vault Access Control

Separation of Material And Personnel

Release of Only Authorized Material

Uniform Packaging

Provide Protection For SNM Material In Transit

OPERATIONAL EVALUATION

Safeguards Controls

Ked Screen Alarms

Container Module Problems

Container Module Sealing 


$\begin{array}{ll}\text { OPERATIONAL EVALUATION (CONT.) } & \\ \text { Container Module Insertion } & 34 \\ \text { Container Module Glove Box } & 36 \\ \text { Secure Transport Module Docking } & 37 \\ \text { Communications } & 37 \\ \text { Operational Evaluation Conclusions } & 38 \\ \text { RADIATION PROTECTION EVALUATION } & 39 \\ \text { Personnel Exposure } & 39 \\ \text { Contamination Control } & 41 \\ \text { Conclusion } & 44 \\ \text { SYSTEMS EVALUATION } & 45 \\ \text { Personnel } & 45 \\ \text { Computer Environment } & 46 \\ \text { Security Operations Center } & 47 \\ \text { MAC Operations } & 48 \\ \text { Systell Reports } & 48 \\ \text { Conclusion } & 50 \\ \text { INDUSTRIAL SAFETY EVALUATION } & 52 \\ \text { Wet Sprinkler System } & 52 \\ \text { Microwave Radiation } & 53 \\ \text { Contamination Control } & 54 \\ \text { CM Handler Latching } & 53 \\ \text { Electrical Terminal Insulation } & 54 \\ \text { Carrousel Rotation } & 54 \\ \text { CM Heating } & 54 \\ \text { Operating Hazards } & 5 \\ & \end{array}$


viii

TABLE OF CONTENTS

(CONTINUED)

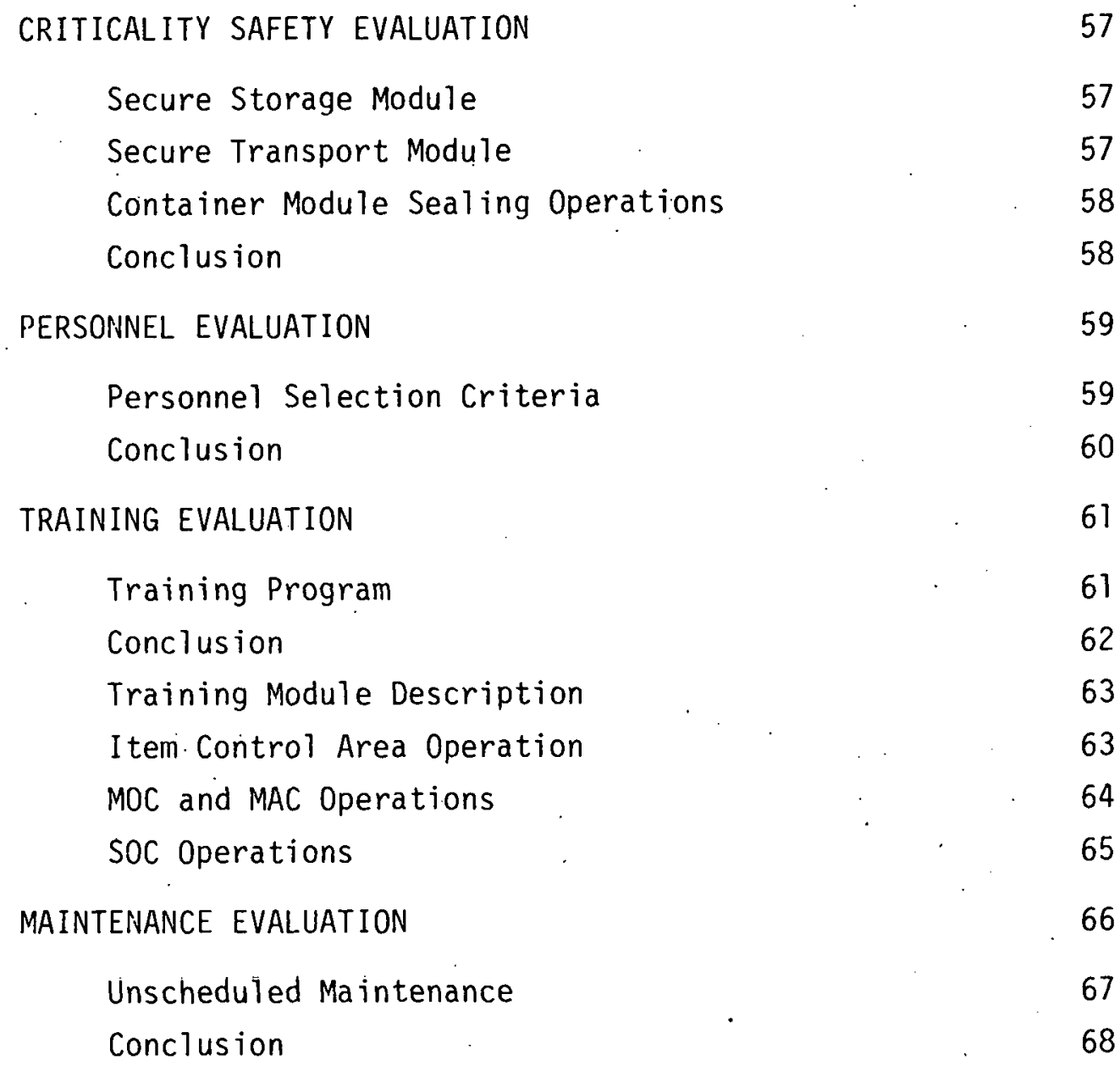




\section{ACRONYMS}

$\begin{array}{ll}\text { CCTV } & \text { Closed Circuit Television } \\ \text { CM } & \text { Container Module } \\ \text { CMP } & \text { Container Module Packaging } \\ \text { CRT } & \text { Cathode Ray Tube } \\ \text { ECR } & \text { Electronic Credential Reader } \\ \text { ICA } & \text { Item Control. Area } \\ \text { JPA } & \text { Job Performance Aid } \\ \text { MAC } & \text { Material Accountability Center } \\ \text { MOC } & \text { Material Operations Center } \\ \text { PPS } & \text { Plutonium Protection System } \\ \text { SNM } & \text { Special Nuclear Materials } \\ \text { SOC } & \text { Security Operations Center } \\ \text { SSM } & \text { Secure Storage Module } \\ \text { STM } & \text { Secure Transport Module }\end{array}$




\section{SUMMARY}

Sandia Laboratories has developed a new plutonium protection system to safeguard plutonium in storage. A prototype of this system has been installed at the Rockwell Hanford Operations, Z-Plant facility. The system was exercised in all phases of its operational design by Z-Plant personnel using special nuclear material. The demonstration was designed to test the system in an operating environment and provide data by which the system could be evaluated.

The Sandia Plutonium Protection System was designed to meet nine specific criteria:

- Protection in depth.

- Release of one unit at a time.

- Release of only that material allowed on an authorized transaction.

- Separation of material and personnel during entry to and exit from item control areas.

- Control of personnel access to the storage area.

- Production of real time inventories.

- Reduction of personnel exposure to radiation.

- Packaging of material uniformly.

- Providing protection for SNM in transit.

During the demonstration the system met all of the design criteria requirements.

Minimum manpower required for material transfers in the present Rockwell storage system is four. The minimum manpower required 
for material transactions in the PPS was five full-time personnel plus four part-time personnel for vault door opening, transaction file initializing and maintenance.

This minimum number could be reduced by locating the security operation center at a central alarm facility which is manned at all times for other purposes.

Based on the Security Operations Center log record of transaction start and completion times, the time required to store SNM in the Plutonium Protection System averaged 0.52 hours per CM. Storage in the presently used Z-Plant vaults averages 0.05 hours per storage container. This increase in time is balanced by the added capability of producing real time inventories.

Hand contact gamma radiation dose rates were reduced by 94 percent when material was packaged in container modules and held in the container module handler. Full body dose rates for storage operations were reduced by 50 percent when compared with that received for storage in existing vaults.

Alarm conditions that required patrol response occurred at an average rate of two times per working shift. This is a prohibitively high rate as each alarm stops the movement of personnel and vehicles in or out of the operating area. Causes of alarms must be reviewed and corrected before the system is acceptable for use in an operating storage facility.

Several operating problems were identified. They involved computer programs, equipment and communications. 
Computer program problems were associated with material handling sequences in the container module packaging room. During one withdrawal transaction computer tracking of one CM failed. The CM was authorized on the transaction, but was processed out of sequence. This should have caused an alarm. Had sequencing instructions been included in the verification portion of the withdrawal program, an alarm would have been sounded indicating material was missing. Program sequencing instructions should be extended to CMP room activities.

Container modules and the secure transport module could be improved by positioning guides to assure alignment with carrousel storage slots and item control area STM docking ports.

Training programs should be improved to help prevent problems associated with operating procedures and computer program communication which must be followed very exactly. Communication confusion caused several transaction aborts. Better operator understanding of the system and computer programs should reduce these transaction aborts.

Efficient maintenance would require a specially trained maintenance crew assigned to the Plutonium Protection System.

Criticality evaluation indicates that the storage system could be extended infinitely for the storage of unmoderated $2.5 \mathrm{kilogram}$ masses packaged in the container module and retained in carrousel storage slots. 
The operational demonstration revealed that the safeguards concepts of the Sandia Plutonium Protection System were compatible with an operational environment. 


\section{DEMONSTRATION PLAN}

The demonstration was divided into three periods, each planned for four weeks duration. Specific predetermined transactions were to be. accomplished during each phase of the operation to determine PPS operational impact on all aspects of a plutonium storage facility. Table I summarizes the actual conduct of the demonstration. Deviations from the planned demonstration were minor and are noted in the comments. As discussed below the demonstration was completed in six rather than twelve weeks.

PHASE I LOADING OPERATIONS

Phase I was planned as a 20 workday period wherein 84 containers of SNM would be deposited in the PPS. The PPS was planned to be loaded by performing at least 20 material deposit transactions. Carrousel one was completely loaded with plutonium oxide. Radiation exposure levels were measured and radiation contours resulting from the one fully loaded carrousel were determined. Carrousel five was completely loaded with plutonium metal. Again radiation contours were determined from two fully loaded carrousels. Plutonium oxide was then loaded into three different carrousels in Bay 1. Inspection/maintenance transactions were conducted during this period.

\section{PHASE II STORAGE OPERATIONS}

Phase II was planned as a 20 workday period beginning after the PPS loading operations had been completed. During this short term storage, the plutonium was monitored by computer and some CM's were relocated to different carrousel locations. Real time accountability/inventory 
was performed by computerized monitoring of the container identities, locations, bulges, and temperatures. Twelve relocations (movement) transactions, involving 48 containers, were scheduled so that other carrousel locations would be tested for operability. Container modules were placed in the top and bottom levels of each carrousel. Inspection/ maintenance transactions were also conducted during this period.

PHASE III WITHDRAWAL OPERATIONS

Phase III was planned as a 20 workday period during which the SNM was to be removed from the PPS. Twenty withdrawal transactions were scheduled to remove the $84 \mathrm{CM}^{\prime} \mathrm{s}$. After removal from the CM's the Rockwell containers were inspected, seal integrity examined, and deposited into an existing Rockwell vault. Inspection/maintenance transactions were conducted during this period. The removal of the last SNM container signaled the end of the demonstration period.

IMPLEMENTATION OF DEMONSTRATION PLAN

Activities in all three phases were completed in fewer workdays than the project demonstration had planned. Staffing the demonstration for eight hours a day, rather than the planned four hours, was a major reason for the reduced number of workdays required to complete all three phases. Operator efficiency, cooperation of Sandia Laboratories personnel, reduction of alarm response action and minimal unplanned maintenance problems were important in the timely completion of the demonstration within the planned commitment.

A11 transaclions were carried out on the day shift. 
The twenty deposit transactions were carried out during the Phase I loading operations. The minimum number of containers in a transaction was two, the maximum was five, which represented one full loading of the STM carrousel.

Transaction identification was numerical. Deposit transactions were authorized by transactions numbered between 33 to 53 (Table I). Deposit transactions times are summarized in Table II. All transaction times are based on the Security Operation Center log record of CMP and vault transaction times.

Carrousel one deposit times are high because of transaction failures and a problem with the carrousel null position microswitch. Manual mode computer operation was necessary to override the switch. This increased the time required for deposits in carrousel one.

Phase II, in-vault movement operations, was completed in five working days. Again staffing the demonstration for eight hour days, rather than the planned four hours, was a major contribution to the reduction in the number of workdays required for this phase.

The first in-vault movement transaction in carrousel one was delayed because of the null position microswitch problem. Correction of this problem, which developed during Phase I, was delayed until Phase II so as not to delay Phase I. Sandia personnel freed the microswitch action. After the switch maintenance, carrousel one could be operated by computer control. Before the switch maintenance, carrousel one door release was done in the manual mode, which caused an increase in the time required for transactions in that carrousel. In-vault movement transaction times are summarized in Tạble II. 
Phase III, withdrawal operations, were completed in ten and one-half working days. Eight hour staffing, a reduction in the number of transaction failures, and minimum maintenance contributed to the rapid withdrawal time.

Withdrawal transactions include a one $\mathrm{CM}$ withdrawal made during the in-vault movement phase. This unit was removed early because the static identification circuit failed. The failed ID was causing a security alarm each time inventory was taken.

Withdrawal transaction times are also summarized in Table II.

Times for transactions in the present Rockwell storage system are included in Table II. These transactions include transfers involving vaults adjacent to the Sandia Plutonium Protection System and those located a substantial distance from the system. 
SUMMARY OF DEMONSTRATION BY TRANSACTION NUMBER

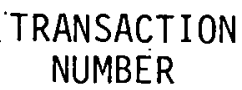

33

34

35

36

37

38

39

40

41

42

43

44

45

46

47

48

49

50

51

52

53

54

55

56

57

58

59

60

61

62

63

64

\author{
TYPE OF \\ TRANSACTION
}

DEPOSIT

DEPOSIT

INSP. \& MAINT.

DEPOSIT

DEPOSIT

DEPOSIT

DEPOSIT

DEPOSIT

DEPOSIT

INSP. \& MAINT.

DEPOSIT

DEPOSIT

DEPOSIT

DEPOSIT

DEPOSIT

INSP. \& MAINT.

DEPOSIT

DEPOSIT

DEPOSIT

DEPOSIT

DEPOSIT

DEPOSIT

DEPOSIT

VAIILT MOVEMENT

VAULT MOVEMENT

VAULT MOVEMENT

VAULT. MOVEMENT

VAULT MOVEMENT

INSP. \& MAINT.

VAULT MOVEMENT

VAULT MOVEMENT

VAULT MOVEMENT
NUMBER

OF CM'S

3

5

0

4

$\cdot 5$

5

5

5

3

0

5

4

2

4

5

0

3

3

5

4

4

5

5

5

5

5

5

4

0

5

5

2
TRANSACTION

TIME-HOURS.

5.3

2.5

0.5

2.5

1.8

3.7

4.8

2.4

1. 5

0.8

2.0

1.4

1.3

1.4

3.0

0.6

1.1

1.1

1.7

1.1

1.4

1.1

2.4

1.4

0.4

0.4

0.9

0.4

0.4

0.4

0.4

0.5 
î

TABLE I CONTINUED

SUMMARY OF DEMONSTRATION BY TRANSACTION NUMBER

\section{TRANSACTION} NUMBER

65

66

67

68

69

70

71

72

73

74

75

76

77

78

79

80

81

82

83

84

85

86

87

88

* 89

* 96

** 97

$\star \star \quad 98$

$\star \star \quad 99$
TYPE OF
TRANSACTION

WITHDRAWAL

WITHDRAWAL

WITHDRAWAL

WITHDRAWAL

WITHDRAWAL

WITHDRAWAL

WITHDRAWAL

INSP. \& MAINT.

WITHDRAWAL

WITHDRAWAL

IMNTHLY COMPUTER MAINT.

WITHDRAWAL

WITHDRAWAL

WITHDRAWAL

TRANSACTION SHEET DESTROYED

WITHDRAWAL

WITHDRAWAL

WITHDRAWAL

WITHDRAWAL

WITHIDRAWAL

WITHDRAWAL

INSP. \& MAINT.

WITHDRAWAL

WITHDRAWAL

WITHDRAWAL

IN VAULT MOVE

IN VAULT MOVE

IN VAULT MOVE

IN VAULT MOVE
NUMBER
OF CM'S

1

5

3

4

5

3

2

0

3

5

0

5

5

5

4

5

5

5

4

3

0

4

4

4

5

2

4

1
TRANSACTION

TIME-HOURS

2.0

1.5

1.2

.1 .4

1.7

1.7

1.7

1.2

1.2

3.9

8.0

1.9

1.7

1.9

3.1

2.5

1.6

1.5

1.9

1.3

1.0

1.2

1.3

1.3

0.4

0.3

0.4

0.2

* Last transaction of demonstration.

** These in-vault move transactions were authorized by out of numerical sequence transactions. 
TABLE II

SUMMARY OF DEMONSTRATION TIME

DEPOSIT TRANSACTIONS

\begin{tabular}{|c|c|c|c|c|c|c|c|c|c|}
\hline \multicolumn{3}{|c|}{$\begin{array}{c}\text { TOTAL } \\
\text { DEPOSITS } \\
\end{array}$} & \multicolumn{3}{|c|}{$\begin{array}{l}\text { CARROUSEL \# } \\
\text { DEPOSITS } \\
\end{array}$} & \multirow[b]{2}{*}{$\begin{array}{l}\bar{X} \text { TIME } \\
\text { PER CM }\end{array}$} & \multicolumn{3}{|c|}{$\begin{array}{c}\text { CARROUSELS } \\
\text { TWO, THREE, FOUR, FIVE } \\
\text { DEPDSITS }\end{array}$} \\
\hline TRANSACTIONS & $C M^{\prime} S$ & TIME & $\begin{array}{c}\bar{X} \text { DEPOSIT } \\
\text { TIME/CM }\end{array}$ & CM's & TIME & & CM's & TIME & $\begin{array}{l}\bar{X} \text { TIME } \\
\text { PER CM }\end{array}$ \\
\hline 20 & 84 & 44 HRS & $0.52 \mathrm{HRS}$ & 35 & 24.5 & 0.70 & 49 & 19.5 & 0.40 \\
\hline
\end{tabular}

MOVEMENT TRANSACTIONS

TRANSACTIONS

12

CM's

TIME

48

6.1 HRS

WITHDRAWAL TRANSACTIONS

TRANSACTIONS

21
CM's

84

ROCKWELL VAULT TRANSACTIONS
$\bar{X}$ MOVEMENT TIME/CM

0.13 HRS

$\bar{X}$ WITHDRAWAL TIME/CM

$0.44 \mathrm{HRS}$ 


\section{DESIGN CRITERIA EVALUATION}

OPERATING STATEMENT

The Rockwell Hanford Operation demonstration of the Sandia Laboratories'designed Plutonium Protection System was conducted to evaluate the PPS as an operational storage facility using special nuclear material.

Eighty-four items of SNM were loaded into, relocated within and then withdrawn from the SSM. These actions were conducted by Rockwell Hanford Operations personnel with minimum guidance from on-site Sandia personnel.

A11 load in, relocation and withdrawal of SNM was done following a preplanned transaction schedule. The SNM transactions were planned to exercise all functions of the PPS. System responses to these operations are used to evaluate the PPS against the design criteria.

\section{DESIGN CRITERIA}

The PPS was designed to specific criteria for the protection and inventorying of SNM. The design criteria are:

- Provide protection in-depth such that, if the vault wall were breached by an adversary the material would still be protected.

- Release to the custodian only one authorized unit at a time.

- Provide a real time inventory of the material in the vault.

- Reduce the radiation exposure to personnel.

- Restrict access to the vault only to those personnel identified with the particular transaction.

- Separate the passage of material from the passage of personnel and monitor the personnel corridor for prohibited articles. 
- Verify that only authorized material is being removed from the vault or being deposited in the vault:

- Package material uniformly for storage in the PPS.

- Provide protection for SNM material while it is in transit.

\section{SAFEGUARDS}

"Black hatting", planned attempts to subvert the system, was not included in this demonstration. However, the basic safeguard system requirements of detection, assessment and response were part of the operational demonstration. Therefore, these safeguard requirements are criteria for evaluating system performance.

\section{PROTECTION IN DEPTH}

The design features that enable the system to meet the criterion of providing protection in depth, are built into the secure storage module. The individual mini vaults within which the storage carrousels are located are second barriers to access to SNM. If the vault room walls were breached, the mini vault and $\mathrm{CM}$ tang deadbolt present another formidable barrier to the adversary.

By inspection it is obvious that this criterion was met. The SSM was built with substantial construction that would prevent an adversary from gaining ready access to SNM. The strength of this second barrier was not challenged by Rockwell.

RELEASE OF ONE UNIT AT A TIME

The system design that assures that the SSM will release only one unit at a time is built into the MAC, MOC, vault computer and carrousels 
themselves. A narrow door provides access into the mini vault and the carrousel. Storage arrangements around the carrousel restrict access to only one container module at a time. This security exists even when all of the CM tang deadbolts are unlocked. This restriction is achieved by arranging CM storage slots in a geometry that fully exposes only one item when a door is opened. A recessed locking pin automatically engages the carrousel after the current transaction CM has been aligned with the door. This prevents manual rotation of the carrousel when the door is open.

Rotation of the carrousel to position the correct CM retaining slot in the access position is under control of the vault computer. Computer agreement on all transaction information must be perfect. Without agreement inter-computer permission for operation and automatic sequencing of actions, which result in access to the SNM, will not be started.

During the operational demonstration, exact control was maintained on the release of SNM from the vault.

The secure transport module (STM) also restricts access to one CM at a time. This material must also be authorized by the current transaction. However, in one move the STM released additional CM's in the CMP room in a sequence that subverted computer control. Operator actions which resulted in subverted computer control were as follows:

- The STM was docked at the CMP.

- Operation was by computer control.

- One CM was removed from the STM, verified and placed in the glove box. 
- All other CM's were removed from the STM and placed in the storage wagon without passing through the verification chamber. This should have caused an alarm.

- Verification of $\mathrm{CM}^{\prime} \mathrm{s}$ was started, but without regard for the correct sequencing of CM's.

- Verification in the out-of-sequence order was accepted by the computer.

- One CM remained to be verified after the verification of the $C M$ which the computer had identified as last in the group.

- The computer did not maintain transaction sequencing or alarm when the last of the transaction CM's was verified ahead of other CM's.

This is a programming deficiency which is correctable by an addition to the computer program.

All programs should be reviewed to assure that sequencing controls and alarms are in place.

REAL TIME INVENTORIES

The design criterion to provide real time inventories requires interaction of several computer activities.

Three types of inventories were taken during the demonstration. The scheduled inventory is a full inventory which is automatically taken on a preset time cycle. The cycle time is program controlled and can be changed. For the demonstration a one hour cycle time was used. The initial scheduled inventory is taken when the system is initially brought on line. At this time the MAC computer automatically 
inventories the secure storage modules. Subsequent inventories are then conducted at the preset cycle time. Any discrepancy will cause an alarm.

By design, when a transaction is in progress at the time the scheduled inventory should be started the inventory is delayed until the transaction is complete, causing the timing cycle to be reset to the time the delayed inventory begins. This delay in inventory means that the inventory period is extended. During this extension accountability is maintained by the vault security systems and the quick inventories which are discussed below.

The quick inventory is a second type of inventory of the SSM's which is taken at the end of each vault transaction while the transaction party is detained in the holding area (i.e., prior to unlocking the ID booth door). This inventory compares information received from the SSM's on the relative location of each CM by ID number with its position as defined by the inventory data base. This is a security inventory which is used to assure that a CM with the correct ID number is located in the currect carrousel. Discrepancy in CM position will cause an alarm.

There is also a quick inventory of the STM. This inventory is taken before undocking and after docking the STM and just prior to the SSM quick inventory.

The third type of inventory is the demand inventory. This inventory is initiated by the MAC operator. This inventory is identical with the scheduled inventory and can be taken at any time outside of a transaction. 
Discrepancy between vault and data base information will cause an alarm. This inventory causes the inventory cycle to be reset. In addition to the above inventories, when not otherwise occupied, the vault computer continually performs a "seal" type inventory. This inventory checks the condition of deadbolts, microswitches and other security equipment. An alarm is sounded if an unexpected change in equipment state is found. The absence of an alarm indicates that all items in the inventory are secure.

Therefore, by a combination of scheduled and quick inventories and continual monitoring of security equipment in the vault, the PPS did provide real time inventories.

REDUCTION OF PERSONNEL EXPOSURE

Storage areas containing large inventories of plutonium have high radiation exposure rates. A design criterion of the PPS is to reduce the radiation exposure rates. Radiation exposure rates were reduced by:

- Placing the radioactive material in the $\mathrm{CM}$ which provides a layer of shielding.

- Using a CM handler that increases the distance between the source material and the operator.

- Storing the CM's in rotating storage cylinders that position material so that direct exposure is received from only two CM's.

- Locating the storage carrousel in a cubicle shielded by concrete and steel.

- Lining the cubicle doors with polyethylene shielding blocks. 
Radiation measurements made as radioactive material was being handled in the PPS, confirmed that radiation exposure rates were reduced by the PPS.

Personnel radiation exposure received during CMP room activities is offset by the personnel exposure savings in transferring $\mathrm{CM}^{\prime} \mathrm{s}$ to the vautt.

In addition to the physical features that reduced the radiation rate, the capability of inventorying the vault by computer reduced the personnel radiation exposure. Manual inventory activity necessary to achieve the same inventory verification confidence provided by the PPS, would require at least one person in the exposure field at all times.

Details of radiation exposure rate changes are discussed in the section on radiation protection.

VAULT ACCESS CONTROL

Control of personnel access to the vault was a design criterion. The criterion was met by integrating the activities of several system components and administrative control.

Personnel were authorized for specific area access within the PPS: Vault, MAC and MOC. This authorization was countersigned by two independently responsible individuals. Authorized personnel information must be entered into the system at the MAC to establish electronic badge identification and the associated photo carrousel slide entries at the SOC. This information was used in conjunction with two electronic badge readers and a face/photo matching system. 
The face/photo check required the SOC patrolman to verify the face/photo match. Door locks were electrically released by the SOC patrolman if the face/photo matched. The patrolman initiated an alarm when the face/photo did not match.

Electronic badge alarms were automatic when the badge being read did not match one authorized by the transaction file.

The walk-through badge reader at the entrance to the personnel corridor was, installed primarily as a system safety feature used to keep track of personnel in the vault. In addition security use of this badge reader was to make a preliminary check that personnel authorized by the transaction that was in progress were indeed present. It was found that this badge reader could be subverted by knowledgeable personnel. This requires holding the badge in such a position that the badge reader did not sense the built-in identity loop. This did occur during the demonstration, however, the individual was quickly identified as an intruder at the outermost security barrier, the vault personnel corridor. ID booth. At this point, the individual was still prevented from entering the vault.

A person not wearing an electronic badge could past the first credential reader, but would be identified as an intruder at the ID booth.

During the demonstration, the PPS did successfully restrict access to the vault to only those personnel identified with a particular transaction.

SEPARATION OF MATERIAL AND PERSONNEL

Basic to the PPS design is the separation of material and personnel. 
This is done by restricting the passage of material when it is being removed from an item control area. The restriction limits the pathway for the removal of SNM to a computer controlled port. The port is not opened unless the STM was docked at that port.

Requiring the STM to be docked before the port is opened, assured that the port is blocked by a vehicle that would secure any material that was passed through. Before undocking from a port, the STM carrousel is positioned so that material in the undocked STM is not exposed.

Personnel enter and exit the vault through a personnel corridor. The personnel corridor is equipped with SNM detectors to assure that SNM is not exiting with operating personnel. SNM passing through the personnel corridor will be detected and cause an alarm at the SOC.

These different exits and the monitoring of personnel assure the separation of personnel and SNM material exiting from the vault. The close proximity of the SSM and docked STM to the SNM portal monitors resulted in the radiation detectors being in a relatively. high radiation field. Activities that caused changes in this radiation field caused alarms. Because of the high frequency of these false alarms, the SNM detectors were disabled on the first day of the demonstration. Quick inventories, taken after personnel had exited the vault, but before they entered the ID booth and the portal metal detector were used to confirm that unauthorized SNM had not been removed from the vault. 
Future storage system installations using SNM portal monitors should have the monitors located outside of any radiation areas or they should be shielded from this radiation.

During the demonstration, the PPS successfully separated material and personnel.

RELEASE OF ONLY AUTHORIZED MATERIAL.

Verification that only authorized material is removed from the vault is achieved by computer control of material security and quick inventories of material at the completion of each phase of a transaction.

Computer control is established by information in the transaction file. This information is used by the MAC and MOC computers to control release of material by the vault computer.

During the demonstration, one transaction caused system ccnfusion on which CM to release. Tang deadbolts were raised on the wrong CM's, but the SSM doors were not unbolted. Unauthorized material was never available for removal from the SSM. This unbolting was the result of errors in the manual mode operation used in a previous transaction.

During the demonstration the PPS did release only that material which was authorized by the transaction.

UNIFORM PACKAGING

The system was to provide uniform packaging of material for storage. A computer/material interface was achieved by electronics built into the container module. All material entering the PPS was computer controlled. Therefore, all material was packaged in container modules. 
Container modules were uniform in construction. All sealing of material in CM's was according to procedures. Therefore, all material was contained in uniform packages.

PROVIDE PROTECTION FOR SNM MATERIAL WHILE IT IS. IN TRANSIT

During the demonstration, SNM material was placed in a secure transport module for transfer between the CMP room and the vault. Material in the STM was inventoried by the MAC computer prior to releasing the STM from a dock. Undocking the STM started a preset timer, which would cause an alarm if the STM was not docked at its pre-established destination before the time cycle lapsed. Material in the STM was inventoried immediately after the STM was docked. at its destination and reconnected to the computer by an umbilical connection.

Computer controlled deadbolts hold the container modules in the STM carrousel. The carrousel is positioned by computer command so that the $\mathrm{CM}^{\prime} \mathrm{s}$ are not accessible during transport.

The STM and computer control did successfully provide protection for SNM material while it was in transit.

The plutonium protection system successfully fulfilled the design criterion while being operated by personnel from the Rockwell Hanford Operation. 
OPERATIONAL EVALUATION

SAFEGUARD CONTROLS

Safeguards controls include all detection equipment and procedures that limit access to SNM or validate that the SNM is in its assigned location. One item of safeguards hardware, the SNM portal monitor used to survey personnel entering and exiting from the vault, was adversely affected by demonstration activities. The adverse effects occurred early in the demonstration and could not be corrected during the demonstration period.

Arrangement of the vault access corridor located the unshielded SNM detectors too close to the vault STM dock and the secure storage module. The SNM detectors were located in the identification booth and were active only during the initial transaction and were adversely affected by radiation from plutonium in the STM and SSM. (Figure 2)

Abrupt changes in the detected radiation rate, triggered "red screen" alarms. This type of alarm stops transaction activities and requires patrol response. Patrol response includes activities to halt all traffic entering and exiting the exclusion area.

An unacceptable false alarm rate resulted in disabling of the SNM. monitors.

Future installations should assure that SNM detectors are situated so that changes in background radiation do not hamper their design function. Shielding the detectors or locating them in areas outside of the radiation field are the options for solving this problem. Shielding may cause some difficulty with bulk. However, locating the detectors 


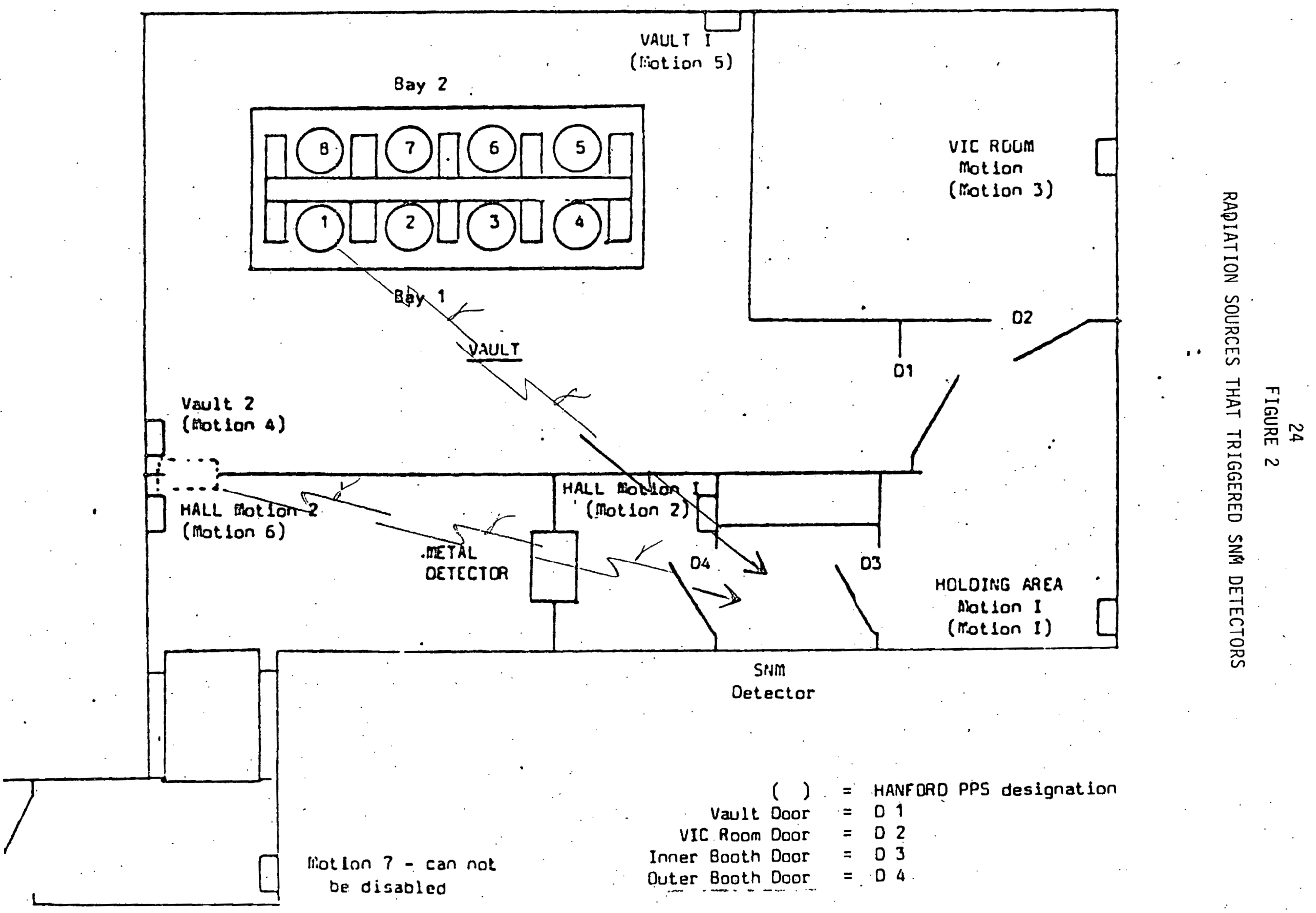


outside of the radiation zone may require moving them an unacceptable distance from the vault.

The original system design had planned for SNM detector shielding. This shielding plan was dropped because of economic constraints. Motion detectors were affected by building vibration and several other unidentified sources of motion. Building vibration affected those units mounted on lath and plaster, plaster board and nonshielding exterior walls. The exterior walls are a sandwich of corrugated aluminum fiber insulation and a sheet steel inner wall. Safeguard protection provided by the vault personnel corridor causes some delay in transaction progression. The average time required by a three person vault party to pass through the personnel corridor and be permitted to enter the vault was 3.5 minutes.

Rockwell Hanford Operations' vault entry safeguards procedures, require on an average 2.5 minutes activity to gain entrance to a storage room. The additional time needed to gain entrance to the PPS vault is used to determine positive personnel identification, measure and store personnel weight information and survey the individual for SNM and ferrous metal. These activities increased the vault safeguards with a small increase in entry time.

Vauit exit time is increased by the "quick inventory" of the SSM after the vault work party has exited from the vault but before entry to the ID booth is permitted. The time required to inventory the SSM, when 84 of the 280 storage positions were ful1, was five minutes. For the demonstration this time required for inventory was not significant. However, if the time required for inventories 
increases arithmetically with the number of SSM's installed, a facility with ten SNM's would experience significant delays for quick inventories of the vault. Consideration should be given to statistical sampling for quick inventories. In a vault with multiple SSM's, inventory of only those SSM's that were opened may be considered an acceptable alternate to a full vault inventory.

\section{RED SCREEN ALARMS}

Alarm conditions were displayed on a CRT in the Security Operations Center. Two levels of alarm condition were displayed. A probable alarm condition was indicated by a yellow screen on the CRT. This condition required CCTV assessment of the situation by the SOC patrolman. An alarm condition was indicated by a red screen on the CRT. This type of alarm required plant patrol response, halting transaction operations, stopping vehicle and pedestrian traffic in or out of the protected area and full investigation of the cause of the alarm.

Sixty-nine red screen alarm conditions occurred during the six-week demonstration period. This number does not include repeats of the original alarm of different red screen alarms that occurred before the original one was cleared. Counting non-redundant alarms raises the total number of alarms to 87 . Red screen alarms occurred on 28 days of the demonstration. The maximum number of red screen alarms cleared in one day was 10 . No alarms were received on twelve days of the demonstration, four of which were demonstration activity days. The others are weekend days during which the PPS was monitoring stored material. 
Responsibility for causing red screen alarms has been divided into two bas'ic categories, system and human. System malfunctions were responsible for causing 62 alarms, human error caused 19 alarms. A combination of system malfunctions and human error caused 5 alarms. Response to a fire drill caused one alarm. The above count includes all non-redundant alarms. Table III is a record of red screen alarms. Nine alarms were for vault inventory discrepancies. If alarms increase linearly with the inventory, a large storage system would spend much of the working time investigating inventory alarms.

The frequency of alarms caused by human error was still high during the last stages of the demonstration. This would indicate that experience in operating the system does not significantly improve operator activities as related to human caused red screen alarms. 
TABLE II I

RED SCREEN ALARM RECORD

\begin{tabular}{|c|c|c|c|c|}
\hline DATE & TIME & ALARM MESSAGE & $\begin{array}{c}\text { TIME } \\
\text { ALARM } \\
\text { CLEARED }\end{array}$ & RESPONSIBILITY \\
\hline $7 / 17 / 78$ & 1445 & Port Door Deadbolt CMP & 1504 & System \\
\hline \multirow[t]{3}{*}{$7 / 18 / 78$} & 0906 & SNM Detector Signal 2 & & System \\
\hline & 0907 & SNM Detector Signal 2 & 0920 & System \\
\hline & 0957 & $\begin{array}{l}\text { Problem with removal of can } \\
\text { l-vault }\end{array}$ & 1007 & System \\
\hline \multirow[t]{6}{*}{$7 / 19 / 78$} & 0420 & Inventory Discrepancy Vault & & System \\
\hline & 0802 & Vault Doors & & System \\
\hline & 0802 & Inventory Discrepancy VauTt & & System \\
\hline & 0802 & $\mathrm{MAC} / \mathrm{MOC}$ & & System \\
\hline & 0804 & MOC - Occupancy & 0813 & System \& Human \\
\hline & 0814 & MOC- Occupancy & 0817 & Human \\
\hline \multirow[t]{6}{*}{$7 / 20 / 78$} & 0254 & Inventory Discrepancy & 0729 & System \\
\hline & 0852 & Inventory Discrepancy Vault & 0914 & System \\
\hline & 0915 & Alarm Condition MAC. & 0935 & System \\
\hline & 0941 & Inventory Discrepancy Vault & Unknown & System \\
\hline & 1009 & Micro Processor Door Open Vault & 1128 & System \\
\hline & 1140 & Micro Processor Door Open Vault & 11.56 & System \\
\hline \multirow{4}{*}{$7 / 21 / 78$} & & & & \\
\hline & 1029 & CMP Ũoor Upen & 1035 & Human \\
\hline & 1414 & Carrousel Discrepans.y r.MP & $14.3 n$ & System \\
\hline & 1431 & Carrousel Discrepancy & 1437 & System \\
\hline $7 / 22 / 78$ & 2154 & Micro Processor Door Open Vault & & System \\
\hline $7 / 23 / 78$ & 0459 & Micro Processor Door Open Vault & 0945 & System \\
\hline
\end{tabular}


TABLE III (CONTINUED)

\begin{tabular}{|c|c|c|c|c|}
\hline DATE & TIME & ALARM MESSAGE & $\begin{array}{l}\text { TIME } \\
\text { ALARM } \\
\text { CLEARED } \\
\end{array}$ & RESPONSIBILITY \\
\hline \multirow[t]{3}{*}{$7 / 24 / 78$} & 1101 & Alarm Condition MAC/MOC & 1106 & Human \\
\hline & 1541 & Carrousel Discrepancy - CMP & 1542 & System \\
\hline & 1603 & Alarm Condition - CMP & 1604 & System \\
\hline $7 / 25 / 78$ & 1106 & Inventory Discrepancy VauTt & 1109 & System \\
\hline \multirow[t]{4}{*}{$7 / 26 / 78$} & 1134 & Alarm Condition MAC/MOC (4)* & 1337 & Human \\
\hline & 1337 & Alarm Condition MOC (3) & 1342 & Human \\
\hline & 1356 & $\begin{array}{l}\text { Unauthorized Request to Open } \\
\text { Door D4-Vault }\end{array}$ & 1400 & System \& Human \\
\hline & 1425 & Alarm Condition MOC (2) & 1434 & Human \\
\hline \multirow[t]{2}{*}{$7 / 27 / 78$} & 1554 & MOC Corriidor Motion Detector & 1557 & System \\
\hline & 1850 & $\begin{array}{l}\text { Micro Processor Door Open } \\
\text { Vault (7) }\end{array}$ & $\begin{array}{c}0839 \\
(7 / 28 / 78\end{array}$ & System \\
\hline $7 / 28 / 78$ & 0839 & Moc. Personnel Count Wrong (3) & 0845 & System \\
\hline \multirow[t]{3}{*}{$7 / 31 / 78$} & 0934 & $\begin{array}{l}\text { Radiation Error in Verification } \\
\text { C.hamher C.MP }\end{array}$ & 0936 & System \& Human \\
\hline & 0943 & " $11 \quad$ " & 1031 & System \& Human \\
\hline & 1244 & CMP Door Magnetic Switch & 1449 & Human \\
\hline $8 / 01 / 78$ & 1501 & Magnetic Door Switch (6) & 1504 & System \\
\hline \multirow[t]{6}{*}{$8 / 02 / 78$} & 0948 & Unauthorized Personnel Present & $\cdot$ & System \& Human \\
\hline & 0950 & Alarm Condition MOC \& Vault & & Human \\
\hline & 0.950 & $\begin{array}{l}\text { ID Booth Occupant does not match } \\
\text { photo MAC/MOC }\end{array}$ & 0.955 & Human \\
\hline & 1238 & Alarm Condition MOC (4). & 1241 & System \\
\hline & 1302 & Alarm Condition MOC & 1306 & System \\
\hline & 1645 & Tamper MAC Motion Detector (3) & 1648 & System \\
\hline
\end{tabular}


TABLE II I (CONTINUED)

\begin{tabular}{|c|c|c|c|c|}
\hline DATE & IIME & ALARM MESSAGE & $\begin{array}{l}\text { TIME } \\
\text { ALARM } \\
\text { CLEARED } \\
\end{array}$ & RESPONSIBILITY \\
\hline $8 / 3 \& 4 / 78$ & 1739 & $\begin{array}{l}\text { Micro Processor Door Open Vault } \\
\text { (14) }\end{array}$ & 0824 & System \\
\hline \multirow[t]{6}{*}{$8 / 04 / 78$} & 1108 & Motion Detector Vault & & System \\
\hline & 1109 & $\begin{array}{l}\text { Unauthorized Personnel Present } \\
\text { Vault }\end{array}$ & & System \\
\hline & 11116 & Inventory Discrepancy - Vault & & System \\
\hline & 1121 & Scale Weight Anomaly - Vault & 1148 & System \\
\hline & 1245 & Tamper MAC Motion Detector & 1247 & System \\
\hline & 1330 & $\begin{array}{l}\text { Micro Processor Door Open Vault } \\
\text { (14) }\end{array}$ & 1345 & System \\
\hline \multirow[t]{2}{*}{$8 / 07 / 78$} & 0924 & $\begin{array}{l}\text { MOC Motion Detector CMP Door } \\
\text { Magnetic Switch (2) }\end{array}$ & 0927 & System \\
\hline & 1508 & MAC/MOC Motion Detector and Doors & 1510 & System \\
\hline \multirow[t]{2}{*}{$8 / 09 / 78$} & 0856 & $\begin{array}{l}\text { Unauthorized Personnel Present } \\
\text { Vauit }\end{array}$ & 0859 & System \\
\hline & 2212 & Micro Processor Door Open Vault (2) & & System \\
\hline \multirow[t]{6}{*}{$8 / 10 / 78$} & 0557 & Inventory Discrepancy - Vauit (4) & 0835 & Sys tem \\
\hline & 0857 & " & 0902 & Sys tem \\
\hline & 0927 & $"$ & 0931 & System. \\
\hline & 1029 & $"$ & 1034 & System \\
\hline & 1056 & " & & System \\
\hline & 1108 & Alarm Conditions MAC/MOC - Vault & & System \\
\hline & - & Alarm Condition MAC/MOC & & Humlan \\
\hline & & Inventory Discrepancy - Vault & & System \\
\hline & & Alarm Condition MAC/MOC & 1126 & Human \\
\hline & 1156 & Inventory Discrepancy - Vault & & System \\
\hline & & Alarm Condition MOC Vault & & System \\
\hline & & Alarm Condition MAC/MOC & & Human \\
\hline & & Inventory Discrepancy - Vault. & 1248 & System \\
\hline
\end{tabular}


TABLE II (CONTINUED)

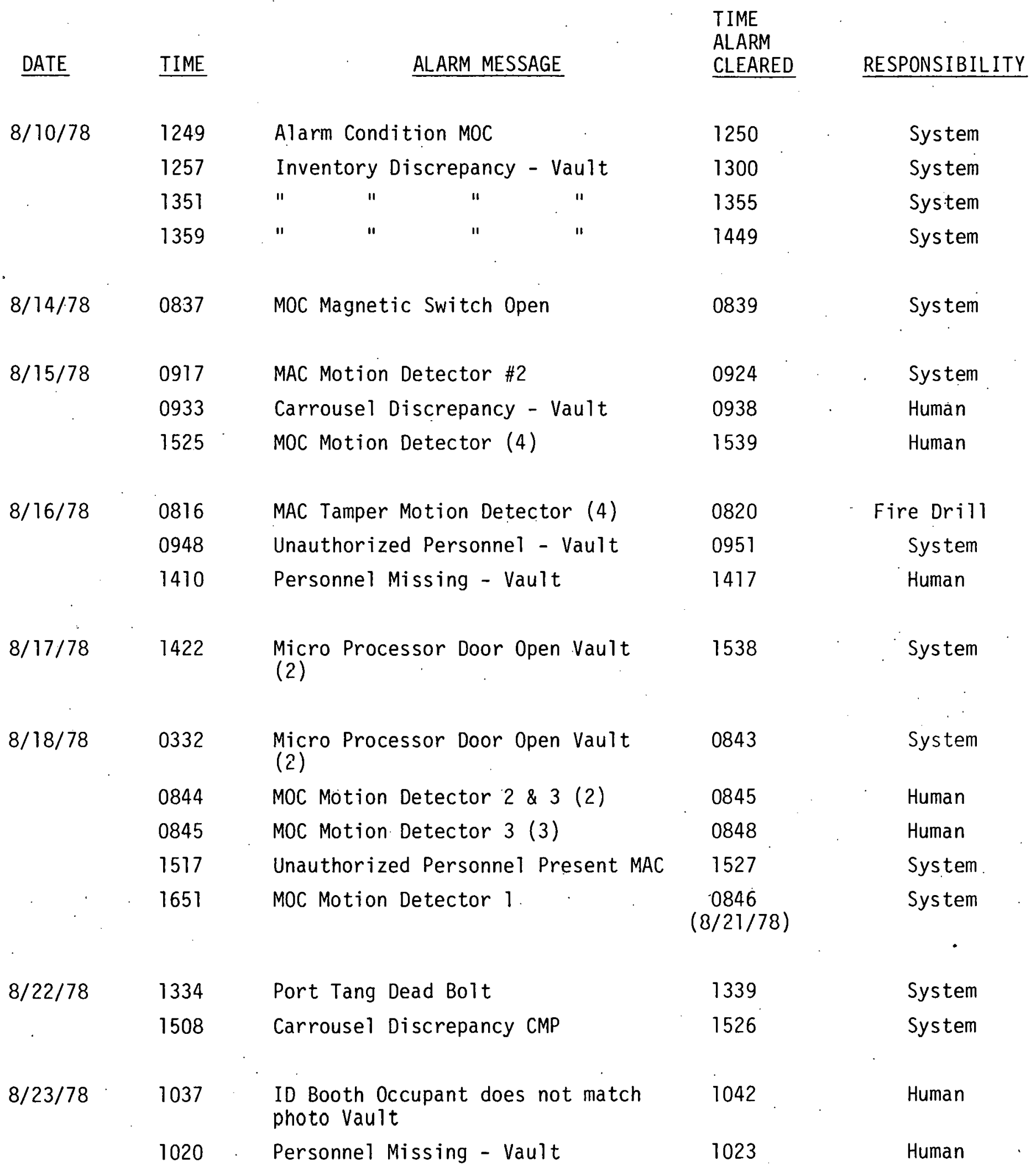


TABLE II I (CONTINUED)

$\begin{array}{lcccc}\text { DATE } & \text { TIME } & \text { ALARM MESSAGE } & \begin{array}{l}\text { TIME } \\ \text { ALARM } \\ \text { CLEARED }\end{array} & \text { RESPONSIBILITY } \\ 8 / 24 / 78 & 1052 & \text { Inventory Discrepancy - Vault } & 1056 & \end{array}$

Numbers in () are the number of alarm repeats before original alarm was cleared. 
The frequency of alarms caused by human error would be reduced by additional training.

The number of alarms that occurred during the demonstration is not acceptable. MOC and SOC logs should be given careful study to identify system improvements which will reduce the frequency of red screen alarms.

Training should be re-examined to be sure that the program is addressing all phases of system operation with adequate intensity. CONTAINER MODULE PROBLEMS

Container modules had a high failure rate. Eighty-four units were deposited in the SSM. Eighty-eight. CM's were used. The four units that failed in the canning process represent a 5 percent failure rate. In a large production program a 5 percent failure rate for a major component may not be acceptable.

Failure causes are listed below:

- Failure to detect temperature changes.

- Broken magnet.

o Static ID failure.

o CM handling tool could not be attached.

The variety of reasons for failure does not indicate any one element to target for improvement. Therefore, CM manufacturers should tighten the overall quality control applied to manufacture and acceptance of $\mathrm{CM}^{\prime} \mathrm{s}$.

In addition to the four CM's that failed during canning, one that was deposited in the SSM had a static identification failure. This unit was removed from the SSM. This failure is especially serious as an in storage failure of static indentification will cause a "red screen" alarm. 
Two other CM's failed in storage due to failure in the temperature measuring circuits. Both units indicated container temperatures of $1000^{\circ} \mathrm{C}$. The temperature on one $\mathrm{CM}$ dropped to $0^{\circ} \mathrm{C}$ after the $\mathrm{CM}$ was handled during the physical check of the temperature. This was followed by a return to $1000^{\circ} \mathrm{C}$ temperature. The temperatures for this unit are logged on Table IV.

When the in-vault failures are included, the total CM failure is seven. This many failures would be intolerable in a production operation.

CONTAINER MODULE SEALING

Sealing and unsealing the two parts of the $\mathrm{CM}$ is the most time-consuming task of the deposit or withdrawal activity. Waiting the seven minutes for the CM to cool makes. CM sealing a lengthy task.

Different solder alloys, reduced heating coil size, different heating technique and perhaps a different closure method should be investigated to reduce the time required to seal and unseal CM's.

\section{CUNIALNER MODULE INSERTION}

Positioning the $\mathrm{CM}$ for insertion into its storage slot could be made with more operator confidence if guides were built into the $\mathrm{CM}$ for aligning the multi-pin connector. The short connector pin contact dnes not produce a sure feel when the contact is made. This could be improved by lengthening the pin contact distance.

Three problems are associated with inserting the CM. These problems are:

- CM alignment.

o Multi-pin connector contact distance.

- Fragile connector pins. 
TABLE IV

CAN \#67

TEMPERATURE, WEIGHT \& BULGE

DATA

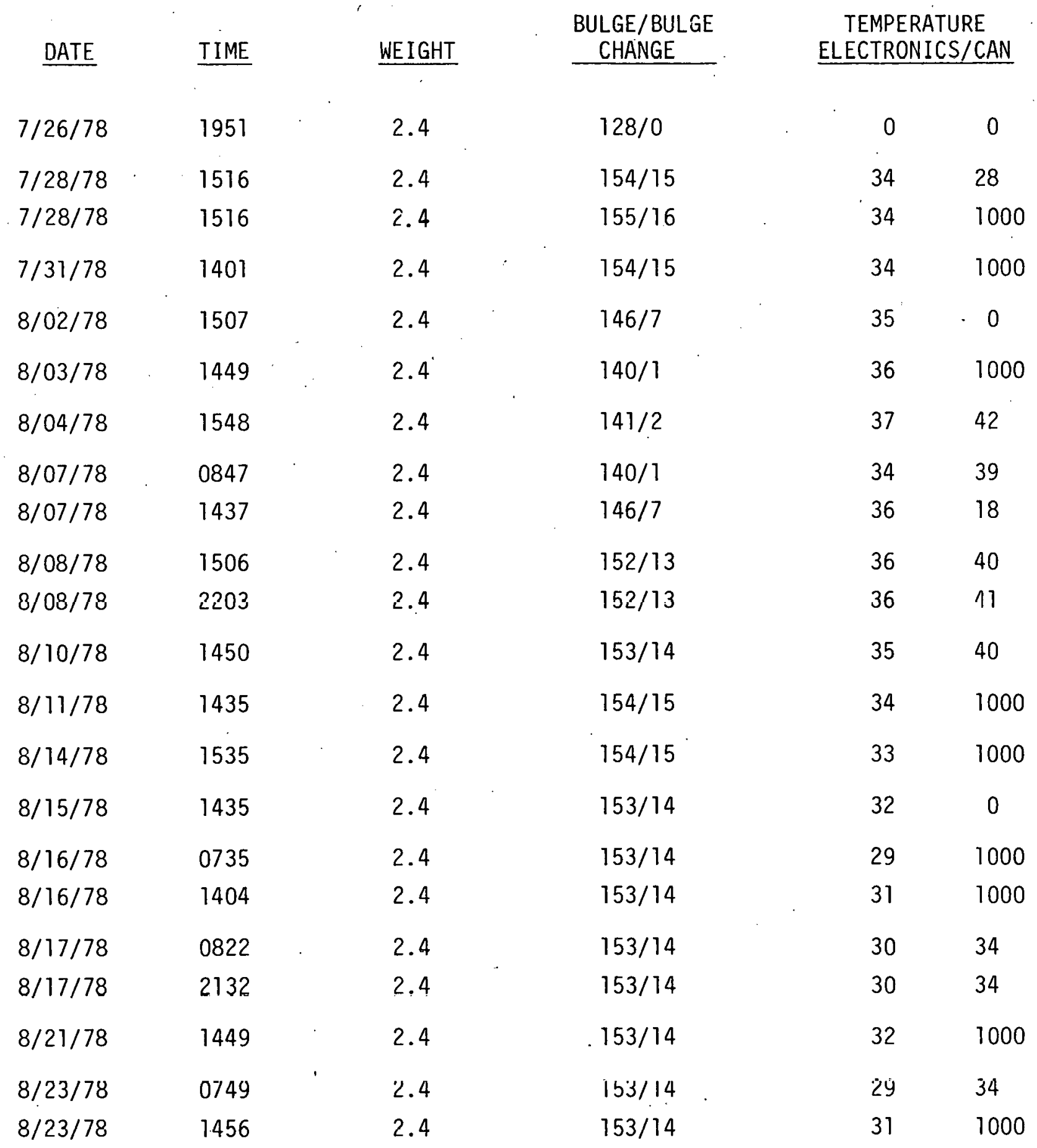


Aligning the CM for insertion would be made with more operator confidence if guides built into the $\mathrm{CM}$. The guides would help assure a first try hook up of the CM.

The short connector pin contact distance does not produce a sure "feel" when the connection has been made. Failure of this connection could cause loss of electrical power to ID circuits when the placement of a $\mathrm{CM}$ is checked for secure storage positioning. An alternative connector design should be developed.

Connector pins are fragile and easily damaged if misaligned when pressure is applied to couple the connectors. Again an alternate design would solve this problem.

Quality control should be improved on container module.electronics. Container modules or their storage slots should be equipped with guides to align the computer connections.

CONTAINER MODULE GLOVE BOX

The potential for contamination exists, but because the material that is being handled is packaged for uncontaminated storage, there is a tendency on the part of the operators to down-grade the contamination potential. To reduce the dependence on operator alertness, an alpha detector should be built into the glove box. The presence of alpha contamination should annunciate outside of the glove box.

Surplus solder has a tendency to splash onto the induction coil. This can cause an electrical short with the coil. An electrical short can cause a fire, reduce efficiency or create a maintenance problem. Two solutions can be applied to prevent these problenis. One is to wrap the coil and its connectors with insulating tape; the other is to place a splash shield around the coil. 
The glove box and heating equipment used for sealing and unsealing CM's was adequate for the demonstration. It may not have adequate alpha contamination detection capability or protection from electrical shorting of the heating system. Attention should be given to improving these two conditions.

\section{SECURE TRANSPORT MODULE DOCKING}

Close alignment is necessary to assure that the STM is in position for deadbolt passage through the docking tang. This alignment is done with the tang hidden from view by the STM body. Guides should be provided to assure correct alignment of the STM for docking.

\section{COMMUNICATIONS}

Work party voice communication with the MAC, MOC, and SOC operators and between members of the work party should be improved. Action delays, some resulting in transaction aborts, were caused by the failure to understand information that was being passed on. Different operating groups have slightly different meanings for the same term. Activities which require precision of information need precise expression and interpretation of that information. Precision in communications between personnel would be had by establishing a common term vocabulary for voice communications.

The system anticipates some failures in work party actions. These actions are given a second chance for completion. The second chance is initiated automatically by the vault computer. Work party personnel were not confident with the short time interval before thé secund chance was given. 
Some method should be developed for communicating an adequate warning to be alert for the second chance operation.

OPERATIONAL EVALUATION CONCLUSIONS

The demonstration found some operational weaknesses in the plutonium protection system's interface with an operating environment. The most serious weakness is the frequency of red screen alarms. Some equipment could be improved to aid the operator in his actions or improve safety. Operating terms should be standardized to aid the understanding of voice communications.

The identified weaknesses do not indicate any problems with the overall PPS concept. Rather they are singular problems which should be correctable without altering the plutonium protection system concepts.

Though conceptually acceptable as a storage system, the PPS could not be accepted for an operational storage facility until the high red screen alarm rate is reduced. 


\section{RADIATION PROTECTION EVALUATION}

\section{PERSONNEL EXPOSURE}

Personnel working in demonstration areas, where exposure to radiation was probable, were equipped with special gamma dosimeters in addition to their regular thermoluminescent dosimeter. These special dosimeters were only worn when the individual was working the PPS demonstration. Exposure recorded on these dosimeters was compared to that received in other Z-Plant storage areas.

In addition to dose determinations, exposure rates from recanning in the CM and use of the CM handler were evaluated.

The dose reduction attributable to the use of the CM is approximately 50 percent for the gamma and 11 percent for the neutron components respectively. In addition, the exposure savings by use of the CM and $C M$ handler combined is 94 percent for the gamma and 67 percent for the neutron components, respectively.

Dose received during CM sealing and SSM deposit operations began at 2.0 mrad per container. This decreased to $0.5 \mathrm{mrad}$ per container as personnel became more proficient in the work. Further reduction could be expected with more experience in handling the material. Information on dose reduction due to use of the $C M$ and $C M$ handler is listed on Table $V$.

The dose received in transferring SNM between the presently used Rockwell storage vaults was approximately 4 mrad per container. The dose received during CMP room activities was 2.0 mrad per CM loading and sealing. This dose was offset by the reduced dose 
TABLE. $\cdot V$

RADIATION DOSE RATE DATA

DOSE RATE WITHOUT HANDLER

BEFORE CIVERPACK

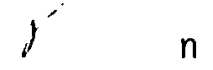

$53 \quad 9$

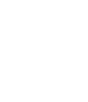

EFORE CIVERPACK

$\begin{array}{ll}j & n \\ ? & 4\end{array}$

$\begin{array}{cc}\text { AFTER } & \text { OVERPAC } \\ 27 & n \\ 27 & 8\end{array}$

DOSE RATE WITH HANDLER

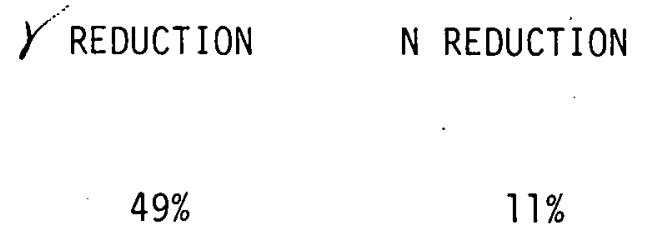

$49 \%$

$11 \%$

TOTAL PERCENT DOSE RATE REDUCTION BY USING OVERPACK AND HANDLER

$\begin{array}{cc}y & n \\ 94 \% & 67 \%\end{array}$


received, 2.0 mrad per $C M$, transferring $C^{\prime}$ 's into the SSM. Additional relocation of SNM, packaged in CM's would be done at a 50 percent reduction in dose.

More reduction in radiation dose would result from the dependency on the automatic inventories rather than requiring in-vault inventories by custodial personnel.

Radiation measurements made in the vault during $C M$ deposit operations indicate a significant reduction in exposure from material in storage. Differing quantities of material in the vaults prevent making the exact in-vault dose comparison. However, the SSM is constructed of the same thickness of concrete as there is in the present shielded storage vault, plus an additional half-inch steel overlay, which should assure additional reduction in dose from stored SNM.

Maximum and average dose from gamma radiation in the presently used shielded storage facility is $40 \mathrm{mr} / \mathrm{hr}$ and $20 \mathrm{mr} / \mathrm{hr}$. With 84 units stored in the SSM, the maximum and average gamma dose rates are 4.0 $\mathrm{mr} / \mathrm{hr}$ and $0.6 \mathrm{mr} / \mathrm{hr}$.

Plutonium protection system vault area dose rates are tabulated on Table VI.

CONTAMINATION CONTROL

There were no contamination incidents during the demonstration. Evaluation of contamination control is based on control procedures that are applied in other operating areas.

The probability of a contamination incident in the PPS is very small. However, the possibility for an incident always exists when radioactive 
materials are present. The sealing hood and SSM are the areas where a contamination incident could have serious consequences for personnel. Because sealing hood operators are working in an uncontaminated hood with material that has a low probability of alpha contamination leakage, visual methods to determine hood glove integrity must be developed. Present methods depend largely on alpha contamination surveys in finger and other difficult viewing areas. This indicator of glove failure does not exist in the sealing hood. Therefore, alternate procedures should be developed for the inspection of hood gloves. 
TABLE VI

\section{PPS IN-VAULT EXPOSURE RATES}

CM'S

IN SSM

8

35

59

72
MAXIMUM GAMMA

EXPOSURE MR/HR

0.5

2.5

2.5

4.0
AVERAGE GAMMA

EXPOSURE MR/HR

0.3

0.5

0.6

$0.4^{*}$

* This anomaly has not been resolved. 
To assure that uncontrolled contaminated material is never removed from the hood, an alpha detector should be located in the hood. Audible signals from the alpha detector should sound outside the hood.

Failure of the inner product can during long term storage is the most probable contamination event in the SSM. This type of incident would be signaled by the can bulge sensor and if caused by metal conversion to oxide would be signaled by temperature measuring equipment which is built into the $\mathrm{CM}$.

\section{CONCLUSION}

Overall radiation exposure rates are reduced by storing material in the PPS.

Exposure rate reduction for handling radioactive materia' in the $\mathrm{CM}$. overpack with the handling tool is significant.

Design of the SSM provides additional layers of shielding which will reduce in-vault exposure. 
SYSTEMS. EVALUATION

PERSONNEL

Three computer equipped control centers were manned during the demonstration. The Security Operation Center was manned by a member of the Plant Protection Department. The Material Operation Center and the Material Accountability Center were run by personnel from the Nuclear Materials Control Department.

Personnel chosen to operate the control centers were selected at random from their work groups. Job requirements for computer operation were not established nor was consideration given to the previous experience, education or aptitude of personnel for computer operations.

The training program used to train personnel to operate the PPS during the demonstration was not as broad in scope or intensive in detail as it would be for an operating facility. The training was basically pragmatic rather than theoretical. Instruction was given on how operations were conducted. Instruction on the why aspect of computer activities was minimal.

Personnel selection techniques and the 1 imited training given for the demonstration may have contributed to ditticulties encountered during some manual mode operations.

Because personnel and the system are not error free, the manual mode of operation is necessary to recover from unplanned conditions. Exact instructions were not prepared for all manual mode situations. Operator evaluation of system condition and the cause of that condition 
will often determine his choice of action. The accuracy of his choice is dependent on his understanding of the system.

During manual mode operation, the operator initiates all computer action commands. To terminate actions, repeat commands and reestablish system condition, specific sequences of commands are required. An operator with a basic understanding of computer system requirements may have been able to command the system with fewer errors. Manual mode operation increases the time required to complete a transaction. During the deposit phase of the demonstration, manual mode was used during the CMP portion of four transactions and during eight vault transactions. This increased the time required for CM handling in the CMP room by ten minutes per. $C M$ and nine minutes per CM in the vault. Manual mode was used four times in the CMP room and six times in the vault during withdrawal transactions. CM handling time in the CMP was increased by three minutes and vault time increased by twelve minutes per CM processed. Though time consuming, this contingency operating mode is necessary to provide operator control of abnormal situations. Operator expertise in computer operation may reduce the time required for manual mode transactions.

\section{COMPUTER ENVIRONMENT}

Computer hardware is relatively temperature sensitive. Room air temperature was not controlled in the MAC/MOC or vault ICA areas. High temperature may have caused a problem in restarting of the SOC computers. Demonstration cost considerations reduced the amount of air conditioning provided for demonstration equipment. This problem is 
not unique to the PPS computers, but affects all computer installations. This does point out the need for special air conditioning in addition to regular supplied air.

\section{SECURITY OPERATION CENTER SYSTEM}

SOC equipment layout could be improved by the following:

- Arrange control area in a semi-circular or half-hexagon configuration.

- Locate alarm CRT and CCTV next to each other.

- Locate line printer at eye level.

- Locate an in-house phone and direct line communications to the emergency officer and patrol radio operators within the SOC operator's reach. Communication equipment should be arranged so that observation of the alarm CRT and CCTV is not lost while communicating.

These improvements are intended to make it possible for the SOC operator to maintain constant observation of the alarm CRT and CCTV monitors whilc performing his other functions.

SOC center control and CRT floor plan. displays were easy to interpret and operate. The arm extension to operate the system is just beyond comfortable reach. The "Yes," "No" and "Sillence" buttons would be more convenient if located in the desk top.

The SOC operator must be as knowledgeable of transaction procedures and sequences as those doing the work. He has a dual application of this information. One is the assessment of alarms. Response activities can be expedited if the SOC operator understands what has happened, how the alarm condition came about and what overall impact the alarm 
has on the system. The second reason for the SOC operator having a high level of system knowledge is activities surveillance by CCTV. He should be able to evaluate work party activity for correct sequencing to assist in preventing loss of computer control. This would be especially important when transactions are in the manual mode.

MAC OPERATIONS

The major problem for MAC operation was errors on transaction forms. This caused delays in establishing transaction files and during the transmission of information between the MAC and MOC. These errors could be controlled by establishing a closer supervision of forms and the entry of information in all spaces on the form which is provided to the operator.

Confusion about when entries were required on a transaction form was the major source of error. The confusion was about which spaces required entries, even when the entry was a zero.

Working in isolation did not cause a problem.

Computer noise levels did not bother operators; however room noise was loud enough to make telephone and intercom communications difficult. Sound deadening boxes should be used with this communicating equipment.

\section{SYSTEM REPORTS}

Five reports were generated daily from the MAC:

- Plutonium Access Control Software (PACS) Inventory Listing (PACSO1) - the number of items in inventory related to specific storage location, transaction number, date and container module (CM) serial number. Table VII: 
TABLE VII

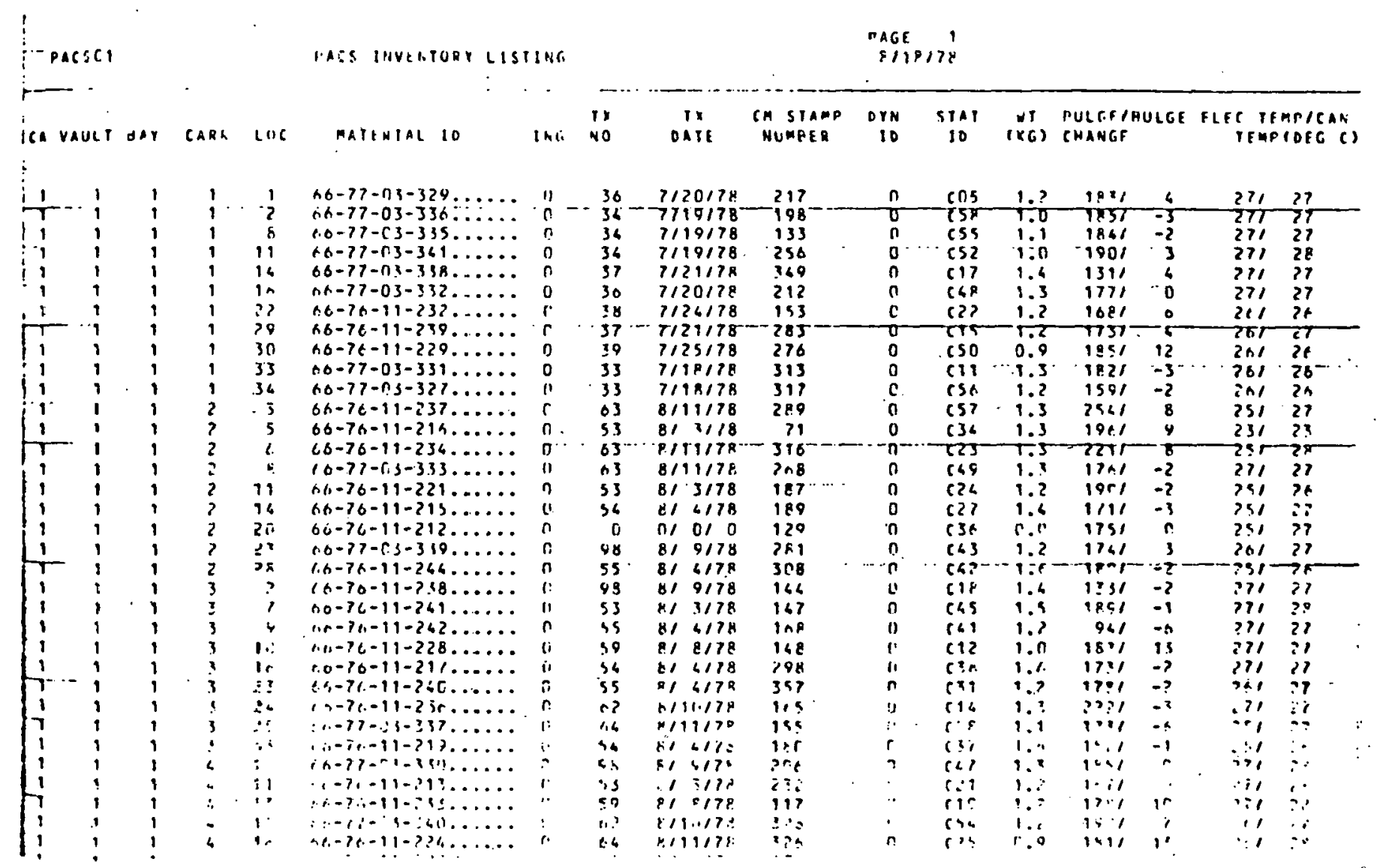


- Plutonium Access Control Software Transaction Listing (PACSO2) lists the transactions from the previous midnight to midnight.

- Plutonium Access Control Software Overdue Transactions (PACSO3) indicates the scheduled times of overdue transactions.

- Plutonium Access Control Software Planned Activity (PACS04) lists all planned transactions.

- Plutonium Access Control Software Activity Log (PACSO5) - lists the software status messages sequenced by time. This log was planned to indicate activities such as personnel entries to the Material Operation Center (MOC), Material Accountability Center (MAC), Security Operation Center (SOC), and vault as well as system failures, alarm acknowledgements, repair activity, etc.

The PACSOl is an inventory listing which included item identity and location. In addition to this identification, the condition of containers is listed. The container bulge change information is a signed number: the sign is opposite to the can bulge. An increase in bulge is a negative number. This tends to be confusing on first reading. The program should be altered to reverse the number signs for printing. The PACS05 report was printed in such a manner that it could not be readily interpreted. The printing of this extensive report caused operating problems. Therefore, it was abandoned early in the demonstration. This report should be redesigned to be more easily understood and generated with fewer major alarms and less system down time.

\section{CONCLUSION}

The computer system operated well when in a temperature controlled environment. Training of personnel should include some basic 
information on computers and general computer operating techniques. Display panels and computer equipment layouts should be reviewed by a human factors engineer. 


\section{INDUSTRIAL SAFETY EVALUATION}

Safety hazards were reviewed by a hazards review team consisting of personnel from several disciplines: development engineering, environmental and occupational safety, instrument and equipment development, geologic storage,engineering technical information systems, and safety and environmental engineering analysis.

Several hazards which are inherent in the Sandia equipment were identified. These hazards would exist at any location where the PPS is installed. The hazards and the corrections applied for the demonstration are given below.

\section{WET SPRINKLER SYSTEM}

- Recommendation: The wet sprinkler system should be tied in with the electrical supply to cut off power and thereby minimize equipment damage if the sprinkler system is activated.

Solution: Fire sprinklers protecting the PPS equipment are wet pipe, individually activated sprinkler heads. They are installed in a sprinkler system that protects areas other than that associated with the Sandia Demonstration. Activation of any sprinkler head in the system will cut off electrical power. Loss of power to computers used in the Demonstration would result in loss of accountability, inability to move carrousels and the increased possibility of diversion of SNM, the Demonstratior: could suffer unnecessary delays if sprinklers in other sections of the system were activated. 
However the electricity/water hazard exists wherever sprinkler systems are used as fire suppressants. Therefore, in a permanent installation a sprinkler system limited to the area occupied by the protected storage system should be considered. Then sprinkler activation would be the result of a fire within the Protected Storage System. The problems would not be caused by activation of sprinklers not associated with the Protected Storage System.

\section{MICROWAVE RADIATION}

- Recommendation: Warning signs be posted in the container module packaging room to alert personnel to the potential hazards of the microwave radiation from the induction heater to heart pacemakers.

Solution: Microwave warning signs were posted at the entrance to and inside the CMP I tem Control Area.

\section{CONTAMINATION CONTROL}

- Recommendation: The CMP glove box/hood be operated as a glove box for unsealing the container modules (CM) to minimize the potential for radioactive contanindiun of the CMP.

Solution: The glove box/hood was used as a containment barrier during the unsealing of CM's.

- Comment: In conjunction with this solution the feasibility of detecting loose radioactive material in the $C M$ was evaluated. This study determined that a reliable means of detecting plutonium leakage from the inner container into the overpack could not be provided with the present CM design. 
CM HANDLER LATCHING

- Recommendation: The CM handler has a potential for dropping the CM's, particularly with the CM handler in the vertical position. Solution: The CM handler was redesigned and tested prior to use.

- Comment: No difficulties were experienced handling CM's with the redesigned $C M$ handler.

\section{ELECTRICAL TERMINAL INSULATION}

- Recommendation: Bare terminals on the deadbolt actuators, powered with 110 volt $A C$, in the carrousels be adequately. insulated to preclude the potential electrical shock hazard.

Solution: All bare terminals were insulated by wrapping with insulating tape.

\section{CARROUSEL ROTATION}

- The need for rotation of the carrousel to a null position after expiration of the established time limit for CM insertion or removal be investigated. Automatic rotation of the carrousel could cause injury to the operator or damage a CM. The adequacy of an audible and visual alarm only should be investigated.

Solution: The computer program was modified to generate an alarm after the preset operating time had lapsed. In addition, the system was set to prevent rotation of the carrousel unless the SSM door is closed.

\section{HEATING}

- Recommendation: Confirm the adequacy of the secure transport module (STM) for maintaining șafe CM temperatures without forced ventilation. 
Solution: Because of its bulky size ( 400 pounds) and the small heat load of five CM's (worst case is 50 watts) no hazard was judged to exist. A test was run to confirm the heat sink calculations.

- Comments: All hazards identified by the Hazards Review Team were reconciled before the demonstration began.

Operation of the Plutonium Protection System did not reveal any hazards that had not been identified by the Hazards Review Committee. It can be concluded that the industrial safety risks associated with the PPS are no greater than those associated with other we11engineered mechanical systems.

OPERATING HAZARDS

In addition to the general hazards identified by the Hanford Hazards Review Team, Sandia Laboratories personnel postulated several accidents which may be possible during the use of Sandia design equipment.

- Event: Preinature activation of Container Module (CM) sealing sequence.

Probable Results: Maybe slight pinching of fingers which would not either bruise the fingers or cut the hood gloves.

- Event: Overheating of $C M$ solder sealing during either a sealing or unsealing operation.

Probable Results: Flammable material or vapors contacting an overheated CM may ignite.

- Event: Accidental dropping of a sealed CM containing SNM. 
Probable Results: When either the multi-pin electrical connector or the Schrader Valve is damaged, there is a danger of rupture of hermetic seals with possible release of contamination.

- Event: Interaction of the Electronic Credential Reader (ECR) with a pacemaker.

Probable Results: May cause a temporary erratic function of the pacemaker. 
CRITICALITY SAFETY EVALUATION

The Sandia Plutonium Protection System was subjected to a rigorous criticality analysis by the Rockwell Hanford Operations, Criticality Engineering and Analysis Section.

SECURE STORAGE MODULE

Criticality analysis determined that an infinite array of carrousels, with 35 storage positions each, in the SSM cubicles would be safe when loaded with 2.5 kilogram, unmoderated plutonium units. Constraints on this storage are:

- Only one unit is to be in each storage position.

- All material is to be contained in Sandia overpacks with the overpacks loaded into position.

No error situations were calculated because of the low probability of making a loading error in the SSM carrousel. Any possible error would be with the original can loading. Since the material to be stored is now in storage, two errors would be required to get a single over-batched unit into the carrousel.

- The plutonium was over-batched and/or mislabeled when it was originally packaged: and

- The error was not detected while preparing the plutonium for storage in the Sandia system.

SECURE TRANSPORT MODULE (STM)

Because of reduced neutron reflection by walls of the STM, the K-effective for 2.5 kilogram units in the STM is less than for those in the SSM. The same two errors as in the SSM are required to load a single error unit in the STM. 
Therefore the STM is critically safe for the transport of $5-2.5$-kilogram units of unmoderated plutonium. The plutonium is to be packaged in Sandia over-packs and secured one unit to the storage position in the STM carrousel.

CONTAINER MODULE (CM) SEALING OPERATIONS

Criticality safety during the CM sealing operation is maintained by a combination of mass, moderation and geometry control. Increased moderation potential was examined in detail.

Two sources of additional moderator, $\mathrm{H}_{2} \mathrm{O}$, were identified. One, the induction heater cooling system, had a potential for delivering up to 15 gallons of water to the sealing hood interior. The resulting water slab was calculated to be safe even in the event that the hood was double batched.

The other moderator source is the fire sprinkler which was located directly over the hood. Because of hood construction, steel and wire reinforced glass with two eight-inch glove ports, breaching of the hood is not credible. Therefore, with no credible source of additional moderation, the $C M$ sealing hood is critically safe even when it contains a double batched unit mass.

CONCLUSION

The Sandia Plutonium Protection System is critically safe for unmoderated 2.5 kilogram unit masses contained in seven-inch-tall fruit cans when the fruit cans are sealed in the Sandia storage CM. 


\section{-PERSONNEL EVALUATION}

\section{PERSONNEL SELECTION CRITERIA}

Personnel trained to operate the PPS were assigned to the demonstration from the Plutonium Operations Department, the Nuclear Materials Control Department, and the Plant Protection Department. Personnel were assigned without special selection criteria. In a continuing plutonium storage. operation there would be advantages to developing special selection criteria for use in staffing the plutonium protection system. Among the criteria should be:

- Long attention spans.

- Ability to work in an isolated environment.

- Patience

- Alertness

- Deductive reasoning ability.

The long attention span is needed to assure that the operator remains attentive to action-indicating devices during holding periods. These periods are of varying duration. To help assure that transactions progress expeditiously, the operator's attention must remain focused so that he can quickly respond to instructions.

Security control of the MAC and MOC areas separates the operators from contact with other personnel. Isolation and the loss of group contact can have a negative effect on some people. An effort should be made to prevent the assignment of these individuals in the MAC or MOC.

The time between a work party request for permission to conduct a transaction activity and computer response to that request is not 
instantaneous. In most cases, the time between the request and the response is short. However, it is an interruption of work flow continuity and can be disturbing to some workers. This disturbance can cause rash or habitual rather than thoughtful actions. This type of operator activity has a high probability of causing problems in operating the PPS. Therefore, patience is a desirable operator character trait. Operators of the PPS must be alert to system instructions and continually aware of their own actions. Several system components require precise operator actions; among these are door request switches, electronic credential readers and the computer input terminals. To prevent delays and complications in transactions, PPS operators must be alert to their actions at all times.

All operating problems, of course, have a cause. Recovery from the problem requires that the cause be identified. Identification of the cause is achieved by reasoning back from the problem through the actions that preceded. This deductive reasoning is necessary to help select the correct recovery actions.

\section{CONCLUSION}

The above criteria apply in varying degrees to every position associated with PPS operation. Therefore, they should be used to select the operating staff. 


\section{TRAINING EVALUATION}

On-site Sandia personnel provided training to Rockwell Hanford Operations personnel. The objective of the training was to prepare the Rockwell personnel to perform proficiently and safely all the functions necessary to operate the PPS during the Operational Demonstration.

\section{TRAINING PROGRAM}

System training was organized around the three major operational areas:

- Item Control Areas (ICA) - CM Packaging \& Vault Storage.

- Material Operations and Accountability Centers (MOS \& MAC).

- Security Operations Center (SOC).

The training for each of the operational areas was conducted in four phases as follows:

1. Introduction

2. Instruction and demonstration.

3. Supervision and practice.

4. Simulated full-scale operation.

The training was organized in modules and, wherever practicable, Rockwel1 procedures were prepared for the PPS demonstration. The modular organization permitted flexibility on the sequence, as well as a :progression from the simplest to the most complex operations. In addition, repeated practice sessions were held as necessary to allow , individuals to obtain an acceptable level of proficiency. Insofar as possible, modules were organized and presented to simulate actual transactions.

Records were maintained on each individual's completion of modules. Each module was signed by one of the instructors as acceptable 
proficiency was achieved. Proficiency was judged by observation of each trainee's performance by an instructor.

CONCLUSIONS

Training presented for personnel to operate the PPS during the demonstration was optimized. In depth, detailed training on the why's of system activity was not used. To train a demonstration-operating staff, limited basic information was presented. The formal training program was designed to prepare a staff for a short-duration operation. Pre-demonstration, on-the-job training gave operating personnel some experience in applying the training.

Traininiz of à staff to man a permanent installation should include a core curriculum of computer information. This would assure that all personnel are learning and working from the same knowledge base. The core knowledge should be applied to specific PPS programs and operating procedures. This should all be tied together in an operational training activity which will train the individual in the application of basic computer knowledge and specific computer programs to operating situations. To gain the highest efficiency in operation, selection criteria should be developed for choosing personnel to man the PPS. 
TRAINING MODULE DESCRIPTION

ITEM CONTROL AREA OPERATION

- The Introduction module consisted of a brief review of the history and development of safeguards concepts, objectives and implementation of the PPS, a glossary of PPS terminology, and a tour of the facilities (3)*

- Simulation of an Inspection/Maintenance transaction consisted of a brief period of classroom instruction and a walk-through demonstration. Following classroom instruction, practice sessions were held with small groups (1ess than 5) under actual system operation conditions.

- An In-vault move transaction, following an instruction and demonstration session, utilized the CM Handler to move empty CM's between locations within the SSM.

- A Deposit transaction Part I started with the insertion of a CM in the Verification Chamber, proceed to the loading of the STM and $i$ ts movement to the vault dock and conclude with the insertion of the CM's into the SSM.

- Deposit transaction Part II similar to Deposit transaction Part I except that operation of the CM Tester and Sealing fixture will be added.

- A Withdrawal transaction Part I made use of the STM to move empty CM's. *The figure in the parenthesis following the module description is an estimated minimum time, in hours, required for the initial instruction and demonstration. Practice time was in addition to this and was variable, dependent on each individual's progress. 
- Withdrawal Part II similar to Withdrawal Transaction Part I, except operations of the sealing/unsealing fixture will be added.

- Full-scale operations encompassed all types of transactions with all other areas in full operation and manned by Rockwell personnel.

MOC AND MAC OPERATIONS

- Introduction.

- The Data input module instructed personnel in the use of computer terminals for the addition of transaction information to the data base.

- Transaction monitoring demonstrated to personnel how a transaction may be monitored by the information displayed on either a line printer or CRT. (2)

Note: A prerequisite, was participation in Deposit and Withdrawal Transaction Part II.

- The Reports module demonstrated the reports which are generated by the MAC and provided instruction on how to generate certain reports. as required.

- System start-up ("Booting") taught personnel the procedures for aborting and re-initializing a transaction and how to start up the entire system including SOC, MOC, MAC and Vault Control.

- Optional (or contingency) control provided procedures on the use of the override and manual options that may be used in extraordinary circumstances.

- Full-scale operations. 
SOC OPERATIONS

- Introduction. (3)

- Participation in Transactions allowed Patrol personnel to be acquainted with normal operations. They participated as observers in simulated transactions.

- A module on the use of Sense Switches (SSW) 0, 1, 2, and 3 trained the SOC operators on the circumstances under which they will be activated and the consequences of such use.

- Full-scale operations. 


\section{MAINTENANCE EVALUATION}

Two types of preventive maintenance were conducted during the demonstration period. One was a weekly check of critical incident alarms (CIA) and constant air monitors by plant forces. The other. was computer maintenance and exercise by a representative of the computer manufacturer.

Entrance to safeguarded areas for CIA checks was made by transaction control. Delays in passing through the safeguards personnel controls increased the time required for these checks. The time was increased from approximately 0.1 hour for CIA's in other areas to 0.65 hours for CIA equipment in the PPS area; a significant increase in time, most of which was needed to pass safeguards controls.

In addition to the increased time required for CIA checks by plant forces, inspection and maintenance entries had a high frequency of safeguards alarms. The alarms were caused by inspection and maintenance party procedure violations. This may be attributable to the limited training given to these people. This type of alarm involves patrol response, thereby increasing the impact of preventive maintenance on other plant forces.

Preventive maintenance by the computer vendor representative was done with MAC/MOC area safeguards controls in the access mode. There were no alarms associated with this activity. However, on restart the computer time settings were re-established twelve hours out of the phase. This was a non-alarm event. The error does emphasize the fact that the PPS requires full-time attention. Unless close attention is given to all changes in routine, errors will occur. 


\section{UNSCHEDULED MAINTENANCE}

Six unscheduled maintenance activities occurred during the demonstration. They were caused by:

- Inoperative microswitch at CMP port door.

- STM carrousel failed to rotate.

- Vault port door deadbolt would not lock.

- Microswitch in carrousel one null position sticking.

- Verification chamber low gamma count.

- Vault microprocessor not reading ID numbers.

A11 maintenance was done by Sandia. personne1. The total time involved in doing the physical maintenance work was four and a quarter hours. Including the time required to diagnose the problem increases the total maintenance time to 26 hours. Sixteen hours of that time was associated with the verification chamber problem.

No major disassembly of equipment was required for maintenance done during the demonstration.

Maintenance was done by personnel who were very familiar with the hardware and the details of its operation. They were specialists on the PPS who were not dividing their time among other activities. Without substantiation, it can be assumed that specialization by Sandia personnel contributed to their maintenance efficiency.

Time required to handle the verification chamber gamma counter problem may be indicative of plant forces maintenance on the PPS. In this case, Sandia personnel were not thoroughly familiar with the equipment. Two days of diagnosis, consultation and discussion with off-site personnel 
were required to determine the extent of the problem and what corrective action could be taken. Physical maintenance activities required to adjust the verifier were completed in approximately 15 minutes after completing consultations with knowledgeable personnel.

\section{CONCLUSION}

The conclusion can be made that a significant savings can be had at the PPS installation by providing in-depth, detailed training for system maintenance personner. Additional savings may be made by assigning maintenance personnel exclusively to the PPS. 